\title{
Convergence auditing: the context of improved billing service - with reference to the experience of British Telecom
}

\author{
Xu Yan \\ Department of Information and Systems Management, Hong Kong University of \\ Science and Technology, Kowloon, Hong Kong \\ Douglas C. Pitt \\ Strathclyde Business School, Glasgow, UK
}

\section{Keywords}

Telecommunications,

United Kingdom, Invoicing

\section{Abstract}

The past decade has witnessed drastic change of British Telecom's (BT) billing system. It has evolved from a system simply issuing a plain paper invoice via its individual branches into a comprehensive system meeting increasingly sophisticated and diversified needs of both residential and business customers. This paper, based on one of the authors' experience in BT Laboratories at Ipswich, will provide an in-depth study to this process. It clearly indicates that the convergence of telecommunications and computing has been a major propellant and facilitator behind the revolutionary advancement of BT's billing service. This conclusion further affirms the critical role played by convergence in current telecommunications deregulation.
Managerial Auditing Journal 14/6 [1999] 312-316

(C) MCB University Press [ISSN 0268-6902]
It has been commonly agreed that convergence of computing technology with that of telecommunications in the early 1980s has brought a revolution to the telecommunications sector (Hudson, 1997). The traditional pattern of natural monopoly is disappearing in more and more countries, while all incumbent telecommunications operators are facing increasingly fierce competition from new market entrants. To defend their leading positions in the market, these incumbent operators are vigorously restructuring their development strategy to a more market-originated one. The drastic improvement of British Telecom's (BT's) billing system is one of the most evident proofs of this change.

Soon after the deregulation, BT constructed an advanced and sophisticated billing platform within a short period of time from mid 1980s to early 1990s. This change is so drastic that it is not premature to claim that there was a revolution in BT's billing system. The in-depth study conducted in this paper reveals that the convergence of computing and telecommunications is not only a strong propellant behind this impressive progress, but also a facilitator that has enabled all the innovations possible.

\section{Basic structure of billing system}

Billing system is mainly an invoicing system with information on payment. The basic structure of billing system for telecommunications is illustrated in Figure 1.

Essentially, billing techniques themselves may be uncomplicated. It was the managerial guideline on how to design the billing system that matters. In China, for example, customers used to pay a fixed rate for every local call, no matter how long the calling time was. Some customers used to talk at length even over the public phone, which became shown as "long-call phenomenon". As a result, the

The current issue and full text archive of this journal is available at http://www.emerald-library.com operator could not acquire payment properly chargeable at customers, and congestion was a serious problem at that time. Since the beginning of the 1980s, the pay-per-unit billing system, which charges the customer by the unit of every three minutes, has been installed nationwide. As a result, economic benefits according to the operator have been greatly improved.

Another example can be found in Britain. Intending to compete with BT, Mercury tried to attract customers by charging them in seconds rather than in units. It illustrated the advantages of this charging method forcibly through strong media projection, mainly on the aspect of fairness. This exerted competitive pressures on BT. As a result, BT announced that it would charge customers in seconds as well from 28 June 1995.

The above examples clearly illustrate that billing system is very critical to the interests of telecommunications operators and customers. They also indicate that there is extremely large space for the billing system to be improved. However, no such evident change happened in BT's billing system before the 1980s.

\section{Convergence: origins for change}

The convergence of telecommunications and computing in the late 1970s has significantly re-shaped the contemporary telecommunications industry. The most extraordinary change that has been brought about by convergence is undoubtedly telecommunications deregulation. This change is so revolutionary that it has entirely re-adjusted the relationship between operators and customers. Operators who once enjoyed privileges of monopoly are now pushed into a market with full-blown competitions. To survive, they have to restructure their development strategies.

In Britain, with the privatisation and deregulation of the telecommunications market in the early 1980s, BT was left to the forefront to compete head-to-head with Mercury and other mushrooming new entrants. 
Xu Yan and Douglas C. Pitt Convergence auditing: the context of improved billing service - with reference to the experience of British Telecom Managerial Auditing Journal 14/6 [1999] 312-316

\section{$\overline{\text { Figure } 1}$}

Basic structure of billing system

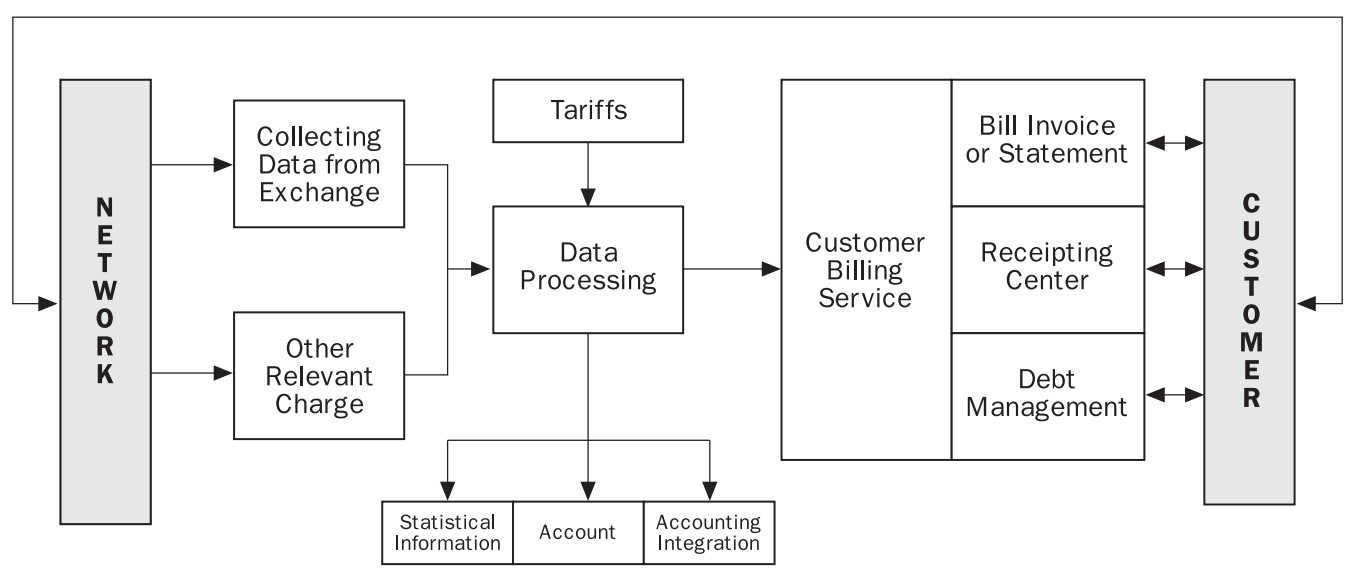

At the same time, the growing awareness of other operators' capabilities of telecommunications raised customers' expectation towards BT. As a result, BT was facing the risk of losing its customers to its newly established rivals.

To win the competition, BT has insistently sought new ways to differentiate its services. As network service has become more of a commodity, customers have increasing expectations and demands of BT's billing service, be they the personal customers, for whom the bill is often the only formal contact with BT, or business customers, for whom the bill is a key item of management information. BT recognised that billing represents a new way to add value to its services, while an advanced billing system is a key competitive weapon that derives competitive advantages (Thames, 1993). Since the mid1980s, radical innovations on BT's billing system have been witnessed.

BT's early efforts on billing system improvement happened in its local area billing service. In 1986, the online customer service system (CSS) was established in 29 different geographic areas. In addition to billing, this system supports many other customer-facing activities including ordering, provisioning, fault repair, accounting, receipting, follow-up and debt management (Mason, 1993).

Billing functions of CSS include:

- Accounting. This ensures that invoices issued and receipts received, including any adjustments, are accounted for accurately, and fed to the accounting and general ledger systems.

- Billing follow-up. The issue of a reminder if a customer fails to pay his/her bill by the due date.

- Debt management. The process to progress the collection of overdue payments including the issue of standard letters.
- Input validation and reporting. Validating and checking the input from exchanges, foreign telecommunications operators, and etc., and collecting the data in appropriate sequences for billing.

- Printing of the cheques. Not only the ability to refund over-payments, but to control that activity in terms of accounting and ledgering these activities.

- Receipting. Collecting and registering the payments made by customers by whatever method they have selected to do this; for example, cash, cheque, budget account, direct debit etc.

- Statistics. Producing a range of reports to assist management and control of the total billing process.

In parallel with the building up of the billing infrastructure, a lot of other innovations have been made. The first is the presentation of the invoice, including the fonts and legends. BT tries to create its corporate image by providing customers with a highly impressive bill invoice. The second is to provide the customer with an itemised and broken-down billing information in addition to the cover page that with total payment. The structure of the invoice format is flexible for business users in order to suit their special need and meet with their requirement of financial accounting. Diagrams could also be provided in order to help companies analyse their spending. The third one is the diversity of bill carriers, this including paper, cassette tape, compact disc (CD) etc. The fourth is to provide special invoices to customers with readability problems, and invoices in the Welsh language are also available (Rockliffe, 1993).

In addition to the above improvement, BT has tried all the ways it can to make service innovations by fully deploying the latest high technology. In September 1997, BT formally 
Xu Yan and Douglas C. Pitt Convergence auditing: the context of improved billing service - with reference to the experience of British Telecom Managerial Auditing Journal 14/6 [1999] 312-316 launched the BT Payment Card. The card is designed for use with the new national bill payment network, Paypoint. With the BT Payment Card, customers are allowed to pay money towards their bills in corner shops, filling stations, newsagents and a host of other local outlets as well as through most post offices and BT shops. The card is swiped through a terminal and the amount paid towards the bill is registered. A receipt confirms the amount. With BT Payment Card, "paying bills will be as painless as possible" (BT, 1997).

Another innovation made by BT is the service called "View my bill". It is an interactive service that allows customers to find out how much they have spent on calls since their last call. The service also allows customers to find out the date that BT plans to send their next bill which will help customers to budget (BT, 1998a)

The results of BT's effort have been very effective. In 1997, the number of residential and business bill accuracy complaints per 1,000 is 1.17 . This represents a customer making a billing complaint once every two hundred years and even then the number of complaints are not the same as the actual number of account errors (BT, 1998b). More importantly, BT has built-up an extremely impressive corporate image through its revised billing system.

This process clearly indicates that it is the deregulated market environment that created incentives for BT to improve its billing system. Bearing in mind that convergence is the major driving force of the contemporary telecommunications deregulation (Hudson, 1997), it is reasonable to attribute BT's recent advancement in billing service to convergence.

\section{Convergence: factor behind the rising demand}

In fact, convergence has not just stimulated operators' incentives for improving billing service, it has also, as illustrated below, raised customers' expectations and demands for a better billing service.

The convergence of telecommunications and computing has significantly improved the efficiency of telecommunications system and has created a cadre of value enhanced services. Additionally, the appearance of Internet has drastically changed the traditional ways of doing business, and electronic commerce is becoming an increasingly popular business pattern. As a result, telecommunications have been widely applied in whole industrial and business sectors.
Simultaneously, expenditure on telecommunications has increased several percent. For small companies, these are not significant figures. But, for giant multinational companies like Ford, it means their common communication expenditures can exceed one thousand million dollars per month, the cost is considerable. In this case, for some business customers, expenditure on telecommunications becomes a key item of management information. Business customers demand a more informative billing service that is more than a simple payment invoice.

To respond with the demand of these business customers, BT launched a so-called Bluesky programme in the early 1990s. This includes several projects, and is committed to improve billing service for business customers. In July 1992, in order to meet with the needs of some business customers who have different geographic locations, the so-called ONEBILL replacing system (ORS) was set up (Payne, 1993). Before the setting up of ORS, branches of a company receive their billing information individually from their local BT offices. Companies have to spend a lot of time and labour to figure out their general spending upon telecommunications. In this case, they demand a consolidated bill that can tell them how much to pay, in total, for all the services provided and want to be presented the details of these charges in a way that best suits their accounting practice. The ORS, by collecting in-time data from CSS in 25 sites with MVS system, provides ONEBILL billing service for hundreds of business customers.

Another example is the implementation of Kenan's billing system for BT's global ventures by BT in 1997. BT has been spearheading its global expansion and investment programme through strategic alliance and joint partnerships throughout the world, as the telecommunications market is gradually deregulated, mainly as a result of the propellant of convergence.

All partners wish to build a strong family of alliances rather than a loose federation of PTTs. Simultaneously, customers located in different nations demand a consistent, locally focused, yet globally deployed customer service, and in particular the provision of the effective billing service.

To provide an ideal solution, BT signed an agreement with Kenan Systems Corporation to distribute Kenan's telecoms-specific billing software. Syntegra, BT's system integration business, will deploy the billing system into family members. By 1998, BT's global ventures are able to provide a consistent and highly effective billing service to their customers (Syntegra, 1997). 
Xu Yan and Douglas C. Pitt Convergence auditing: the context of improved billing service - with reference to the experience of British Telecom Managerial Auditing Journal 14/6 [1999] 312-316

\section{Convergence: instruments for change}

Interestingly, convergence has not only raised customers' demands for a better billing service and has stimulated operators' incentives to improve billing service, but it has also provided the availability for the change. The electronic data interchange (EDI) billing system, as stated below, is one of the evidences.

Some giant companies, whose spending on telecommunications is very high, demand a real-time billing system enthusiastically in order to get the latest management information. To meet the needs of them, BT set up an EDI system in 1992 (Recketts and Davis, 1993). It acts like a huge database, with information collected from CSS and ORS. Under the control of BT EDI Gateway, customers can get access to their up-to-date information through communications between their own EDIs and BT EDI. As EDI is a computer communications system, it can be taken as a typical model of convergence.

BT's case is not unique, as another example can be found in AT\&T's billing system. AT\&T published AT\&T billing Edge Desktop Analysis Software for its largest customers of 800 toll-free service in 1995. It is a complete information management tool that can significantly expand the analysis power to get important management information. AT\&T will provide a free CD-ROM on a monthly basis with all relevant billing and other business information recorded. This free service was further expanded in 1996 when 888 prefix joined 800 for toll-free service (AT\&T, 1995). The application of this software has greatly improved AT\&T's billing service.

\section{BT's billing platform}

After consistent efforts since deregulation, BT has built up a comprehensive multiservice billing system, which will act as a platform for BT's future advancement of billing service (Crookes, 1997). The infrastructure of this system can be illustrated by the diagram shown in Figure 2.

There is no doubt that a modern and flexible billing platform has been set up by BT. Customers, from individual residents to giant companies, can get satisfactory billing service. Simultaneously, BT has built up an impressive corporation image through this systematic change.

\section{Convergence: broadway for future}

The importance of convergence to billing service improvement is actually not just limited to what has already been achieved. There is huge potential to be further explored. One of the examples is the so-called $\mathrm{CPE}$ bill invoicing and paying system, which is being developed by BT and other operators.

For the CPE system, there are several options. One of them, which will soon be partly available in BT's Billing 90 project, is to use telemetric technique where all meters, mainly facility meters like that of gas, electricity and water, in a household are remotely connected to BT by telephone line and customers can read their bill through a terminal installed in their homes, or probably through the late available interactive television service (Figure 3). In the future, all kinds of bills can be invoiced through the personal computer connected with Internet and customer could pay through tele-banking system. The application of this system can reduce the cost for bill invoicing and collection, not just for telecommunications, but for gas, electricity and other companies also. By charging commission fees to these companies, BT's resource of revenues is further expanded. At the same time, the incorporation of new technologies into this system will also refresh BT's already created image of high-tech corporation.

\section{Conclusion}

BT's billing system has changed drastically in the last decade. As discussed in this paper, convergence of telecommunications and computing has been one of the strong propellants behind this revolution.

First, the convergence led to a highly deregulated environment. Operators that once enjoyed monopoly privileges have been propelled to the forefront of the increasingly competitive market. In response to this, BT extended its development strategy from improving operational efficiency and optimising network technology to meeting the market needs. Improvement of BT's billing system is a clear evidence of these efforts.

Second, the convergence has made telecommunications increasingly an integrated part of business operations. Expenditure on telecommunications is now a vital item of management information. This raised the demand of business customers to an advanced billing service.

Third, it is convergence that has made improvement on billing system possible. EDI, CD-ROM, multimedia and other converged technologies have provided an array of instruments that make ingenuity possible.

Lastly, the convergence will provide huge potentials for future development of the billing system. This is not only just in terms that 
Xu Yan and Douglas C. Pitt Convergence auditing: the context of improved billing service - with reference to the experience of British Telecom Managerial Auditing Journal 14/6 [1999] 312-316

\section{$\overline{\text { Figure } 2}$}

BT's billing platform

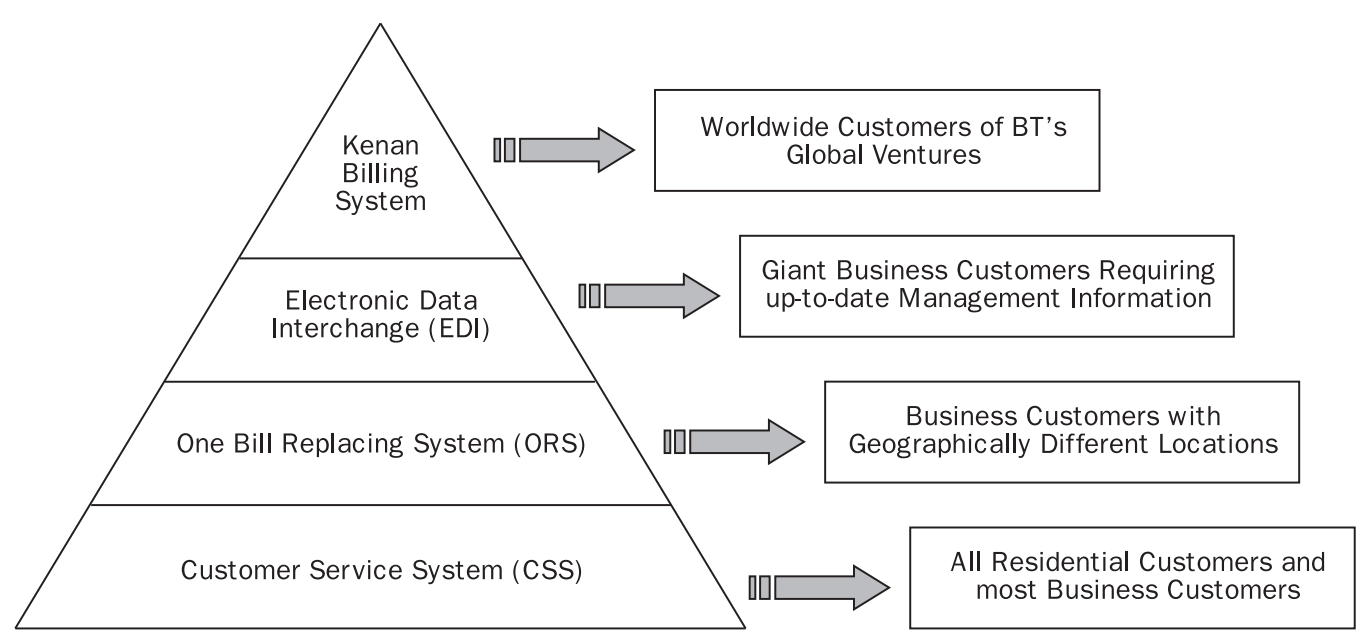

\section{$\overline{\text { Figure } 3}$}

Future bill invoicing and paying system

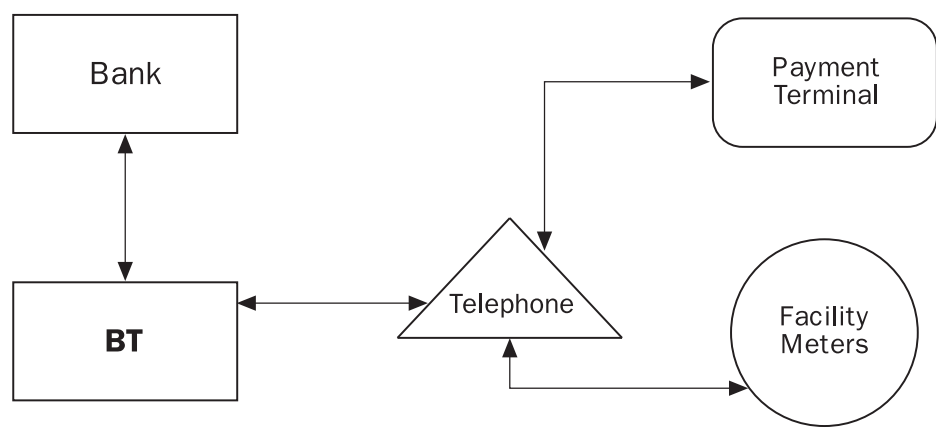

more and more new technologies can be developed to enhance further the current billing system, but also in terms of opportunities for creating new resources of revenues.

With the further development of convergence, BT's billing system will undoubtedly face new challenges and opportunities in the future. In April 1998, Oftel, the regulator of telecommunications in the UK, issued a document on intention of lifting the restrictions on national telecommunications companies providing broadcasting services to homes over their networks. This implied that BT, together with other telecommunications operators, could soon join the broadcasting market and provide multi-media service to customers (BT, 1998c). With the diversity of services provided, a more sophisticated billing system and billing scheme is required. Simultaneously, it also provides more opportunities to BT. For example, a bill invoice can be provided in the form of multimedia, and the future interactive digital TV will provide an ideal way of bill payment.

The case of BT further affirms the critical role of convergence in current telecommunications deregulation. Both the operator and regulators should insistently and consistently explore advantages of convergence further.

\section{References}

AT\&T (1995), AT\&T News Release, 11 September. BT (1997), BT Launches Bill Payment Card, News Release, 18 September.

BT (1998a), "View my bill", http://www1. btwebworld.com/shopathome/cvompaigien/ concrete/ viewmybill/viewmybill.html

BT (1998b), BT Keeps the Customer Satisfied, News Release.

BT (1998c), New Multimedia Opportunities for BT, News Release.

Crookes, J. (1997), "Multiservice billing system - a platform for the future", British Telecom Technology Journal, Vol. 15 No. 1, January, pp. 98-113.

Hudson, H.E. (1997), Global Connections: International Telecommunications Infrastructure and Policy, Van Nostrand Reinhold, New York, NY.

Mason, G. (1993), "Evolution of BT's billing system", British Telecommunications Engineering, Vol. 11 No. 4, January, pp. 262-8.

Payne, G. (1993), “The ONEBILL development”, British Telecommunications Engineering, Vol. 11 No. 4, January, pp. 292-9.

Ricketts, M. and Davis, H. (1993), "EDI billing", British Telecommunications Engineering, Vol. 11 No. 4, January, pp. 285-91.

Rockliffe, R. (1993), “Implementing BT's new bill”, British Telecommunications Engineering, Vol. 11 No. 4, January, pp. 273-8.

Syntegra (1997), Syntegra to Implement Kenan's Billing System for BT's Global Ventures, Press Release, 8 July.

Thames, G.D. (1993), "Syncordia's billing service”, British Telecommunications Engineering, Vol. 11 No. 4, January, pp. 241-5. 